\title{
Editorial
}

\section{Identification and treatment of patients with atrial fibrillation in primary care}

Atrial fibrillation is the most common cardiac arrhythmia. The principal significance of atrial fibrillation, both to patients and health care systems, is the fivefold increased risk of embolic stroke. ${ }^{1}$ Atrial fibrillation is associated with $15 \%$ of all strokes ${ }^{2}$ and with $36 \%$ of strokes in patients older than 80 .

Renewed interest in atrial fibrillation has followed publication of randomised controlled trials showing that anticoagulation is effective in decreasing this risk of stroke..$^{3-7}$ The effect size for warfarin is huge with a $68 \%$ relative risk reduction for stroke in the primary prevention trials, with annual stroke risk reduced from $4.5 \%$ to $1.4 \%$ and number need to treated (NNT) for one year of $32 .{ }^{8}$ In secondary prevention the effect size is even greater with a $66 \%$ relative risk reduction, annual risk reduction from $12 \%$ to $4 \%$, and NNT for one year of only $12 .^{9}$ The data on aspirin are less impressive, with the $21 \%$ risk reduction only just reaching significance. ${ }^{10}$ Reliable data on the newer antithrombotics in atrial fibrillation are not currently available.

Reductions in stroke risk not only have obvious benefits to patients; stroke has a high cost to all health care systems with 1000 new cases per 500000 population per year, expending around $5 \%$ of National Health Service resources in the UK.

To maximise health gain, the first essential step is to identify patients with atrial fibrillation and determine who would have most to gain from anticoagulation. Inevitably, this will involve a substantial role for the primary care physician as most patients with atrial fibrillation are based in the community without specialist follow up. Unfortunately, the condition is often unrecognised by both clinicians and patients. In one population based survey of patients over 65 in northern England, only $76 \%$ of patients with atrial fibrillation were known to their family doctor. ${ }^{11}$ In a similar large study involving electrocardiographic screening in central England, only $31 \%$ of patients with atrial fibrillation were recognised (Hobbs FDR. Consensus conference on the management of atrial fibrillation. Royal College of Physicians of Edinburgh, Edinburgh, 1998). These studies also provide an estimate of the numbers of patients who may need to be considered for anticoagulation as current rates of warfarin use in identified atrial fibrillation patients were between $25 \%{ }^{11}$ and $50 \%$ (Hobbs FDR. Consensus conference on the management of atrial fibrillation. Royal College of Physicians of Edinburgh, Edinburgh, 1998). Therefore, based on current levels of underdiagnosis and possible underanticoagulation, the UK might see up to a fivefold increased use of warfarin in atrial fibrillation, assuming all patients identified are deemed appropriate for anticoagulation. It is estimated on Scandinavian data that the costs of such anticoagulation would be repaid by the costs of the strokes averted. ${ }^{12}$

However, these data do not take account of some of the unanswered questions around atrial fibrillation. The first is how far current underutilisation of warfarin by primary care physicians is appropriate? Despite the evidence on treatment benefits, concerns continue over how widely the data from the highly selected hospital populations used in the treatment trials are relevant to the undifferentiated and largely elderly patients seen in primary care. ${ }^{13}{ }^{14}$ Practising clinicians, who are more likely be influenced in management decisions by treatment risks above treatment benefits, ${ }^{15}$ may underutilise anticoagulation by believing that studies have overestimated the size of treatment effect and underestimated treatment risks. In the case of anticoagulation, physicians overestimate the risk of haemorrhage in patients on warfarin. ${ }^{16}{ }^{17}$ Such fears not only influence primary care practice; similar concerns among hospital specialists contribute to only $37-60 \%$ uptake of warfarin in eligible patients in US hospital practice. ${ }^{18-22}$ Overemphasis of treatment risk is also a factor in primary care underuse of angiotensin converting enzyme inhibitors in heart failure. ${ }^{16} 23$

Uncertainties over atrial fibrillation treatment strategies particularly relate to patients over 75 , in whom anticoagulation may be more hazardous. Further trials are needed to identify the ideal international normalised ratio (INR) target range for such patients-for example, a target INR range of 1.6-2.5 has yet to be tested in a clinical trial.

Further unanswered questions relate to screening for atrial fibrillation. The ideal method of screening has yet to be evaluated. Palpation of pulse by trained nurses in primary care has a high sensitivity but a low positive predictive value of $8-23 \% .^{24}$ Pulse measurement may therefore prove an appropriate filter to determine patients requiring further investigation in whatever programme of atrial fibrillation screening that emerges.

In terms of stratifying atrial fibrillation patients' suitability for anticoagulation, the role of echocardiography is yet to be prospectively assessed. On the basis of the SPAF 3 (stroke prevention in atrial fibrillation) data, ${ }^{25}$ the only independent contribution made by echocardiography appears to be assessment of ventricular function. Preliminary data suggest that in routine practice the use of echocardiography would add little to the decision over need for anticoagulation. ${ }^{26}$ Applying SPAF 3 clinical indications for anticoagulation to two UK studies reveals minimal additional information is gained from echocardiography. In one study only one of 127 patients over 65 had an echocardiographic risk factor but no clinical indication ${ }^{27}$; and in the second study, only $3 \%$ of patients over 45 years had (borderline) abnormalities on echocardiography in the absence of another clinical indication for anticoagulation, namely ejection fractions of $40-50 \% .^{28}$

The final major issue to be determined in management of atrial fibrillation is, once anticoagulated, whether primary care can offer reliable monitoring of INR. ${ }^{29}$ Recent UK data showed that the use of computerised decision support software alongside a near-patient test for INR can result in significant improvements of INR control in primary care clinics compared to routine hospital follow up, ${ }^{30}{ }^{31}$ with results persisting in routine practice outside the trial. ${ }^{32}$ Such data are important as, if anticoagulation of atrial fibrillation patients is to increase substantially, varied methods of reliable warfarin monitoring will be needed.

The increased evidence base on atrial fibrillation management has helped to focus more attention on the importance of the problem. However, as long as uncertainties remain over which patients with atrial fibrillation have 
most to gain from anticoagulation, and how this stratification should be determined, it is likely that clinicians will continue to be seen to underperform. In the meantime, clinical guidelines on the topic should emphasise those recommendations that are unequivocal and those for which additional evidence is awaited.

RICHARD HOBBS

Professor of Primary Care and General Practice,

Medical School, University of Birmingham,

Edgbaston, Birmingham B15 2TT, UK

email:f.d.r.hobbs@bham.ac.uk

1 Wolf PA, Abbott RD, Kennel WB. Atrial fibrillation as an independent risk factor for stroke: the Framingham study. Stroke 1991;22:983-8.

2 Wolf PA, Abbott RD. Kannel WB. Atrial fibrillation: a major contributor to stroke in the elderly. The Framingham study. Arch Intern Med 987;147:1561-4.

3 The Stroke Prevention in Atrial Fibrillation Investigators. Stroke prevention and atrial fibrillation study: final results. Circulation 1991;84:527-39.

4 Connolly SJ, Laupacis A, Gent M, et al. Canadian atrial fibrillation anticoagulation (CAFA) study. F Am Coll Cardiol 1991;18:349-55

5 Peterson P, Boysen G, Godtfredsen J, et al. Placebo-controlled randomised trial of warfarin and aspirin for prevention of thrombo-embolic complications in chronic atrial fibrillation. Lancet 1989;i:175-9.

6 The Boston Area Anticoagulation Trial for Atrial Fibrillation Investigators. The effect of low-dose warfarin on the risk of stroke in patients with non rheumatic atrial fibrillation. N Engl f Med 1990;323:1505-11.

7 Ezekowitz MD, Bridgers SL, James KE et al. Warfarin in the prevention of stroke associated with non-rheumatic atrial fibrillation. Veterans Affairs Stroke Prevention in Non-rheumatic Atrial Fibrillation Investigators. $N$ Stroke Prevention in Non-rhe
Engl f Med 1992;327:1406-12.

8 Atrial Fibrillation Investigators. Risk factors for stroke and efficacy of antithrombotic therapy in atrial fibrillation: analysis of pooled data from five randomised controlled trials. Arch Intern Med 1994;154:1449-57.

9 EAFT (European Atrial Fibrillation Trial) Study Group. Secondary prevention in non-rheumatic atrial fibrillation after transient ischaemic attack or minor stroke. Lancet 1993;342:1255-62.

10 Atrial Fibrillation Investigators. The efficacy of aspirin in patients with atrial fibrillation: analysis of pooled data from 3 randomised trials. Arch Intern Med 1997;157:1237-40

11 Sudlow M, Rodgers H, Kenny RA, et al. Population based study of use of anticoagulants among patients with atrial fibrillation in the community. $B M \mathcal{F}$ 1997;314:1529-30

12 Gustafsson C, Asplund K, Britton M, et al. Cost effectiveness of primary/prevention in atrial fibrillation: Swedish national perspective. $B M \mathcal{F}$ 1992;305:1457-60.

13 Sweeney KG, Gray DP, Steele R, et al. Use of warfarin in non-rheumatic atrial fibrillation: a commentary from general practice. $\mathrm{Br} \mathcal{F}$ Gen Pract $1995 ; 45: 153-8$
14 Pringle $M$, Churchill $R$. Randomised controlled trials in general practice. BMF 1995;311:1382-3.

15 Hobbs FDR, Wilson S, Jones MI, et al. European survey (EuroHF) of primary care physician perceptions and practice in heart failure diagnosis and management. Eur Heart f 1998;19:S156.

16 Sulch D, Bridger S, Sudlow M, et al. Warfarin use in patients with atrial fibrillation [letter]. BMF 1997;315:750.

17 McCrory DC, Matchar DB, Samsa G, et al. Physician attitudes about anticoagulation for non-valvular atrial fibrillation in the elderly. Arch Intern Med 1995;155:277-81.

18 Albers GW, Yim JM, Belew KM, et al. Status of antithombotic therapy for patients with atrial fibrillation in university hospitals. Arch Intern Med 1996;156:2311-16.

19 Bratzler DW, Murray CK, Moore LL. Warfarin use in Medicare patients with atrial fibrillation. Arch Intern Med 1997;157:1613-17.

20 Munschauer FE, Priore RL, Hens M, et al. Thromboembolism prophylaxis in chronic atrial fibrillation: practice patterns in community and tertiary care hospitals. Stroke 1997;28:72-6.

21 Whittle J, Wickenheiser L, Venditti LN. Is warfarin underused in the treatment of elderly persons with atrial fibrillation? Arch Intern Med 1997;157: $441-5$

22 Antani MR, Beyth RJ, Covinsky KE, et al. Failure to prescribe warfarin to patients with non rheumatic atrial fibrillation. $\mathcal{F}$ Gen Intern Med 1996;11:713-20.

23 Houghton AR, Cowley AJ. Why are angiotensin converting enzyme inhibitors underutised in the treatment of heart failure by general practitioners? Int 7 Cardiol 1997;59:7-10.

24 Sudlow M, Rodgers H, Kenny RA, et al. Identification of patients with atrial fibrillation in general practice: a study of screening methods. BMF 1998;317:327-8.

25 Stroke Prevention in Atrial Fibrillation Investigators. Adjusted-dose warfarin versus low-intensity, fixed-dose warfarin plus aspirin for high-risk patients with atrial fibrillation: stroke prevention in atrial fibrillation III randomised controlled trial. Lancet 1996;348:633-8.

26 Hart RG. Consensus conference on the management of atrial fibrillation. Edinburgh: Royal College of Physicians of Edinburgh, 1998.

27 Sudlow M, Thomson R, Thwaites B, et al. Prevalence of atrial fibrillation and eligibility for anticoagulants in the community. Lancet 1998;352:1167-71.

28 Davis RC, Hobbs FDR, Lancashire RJ, et al. Prevalence of atrial fibrillation and associated cardiac abnormalities in the general population and in highrisk groups. Eur Heart f 1998;19:S446.

29 Hobbs FDR, Fitzmaurice DA. Where should oral anticoagulation monitoring take place? Br f Gen Pract 1997;47:479-80.

30 Fitzmaurice DA, Hobbs FDR, Murray ET, et al. Evaluation of computerised decision support for oral anticoagulation management in primary care. $\mathrm{Br}$ f Gen Pract 1996;46:533-5.

31 Hobbs FDR, Fitzmaurice DA, Rose PE, et al. A randomised controlled trial of community versus secondary care management of atrial fibrillation thromboprophylaxis with warfarin. Eur Heart f 1998;19:S248.

32 Fitzmaurice DA, Hobbs FDR, Murray ET. Primary care anticoagulant clinic management using computerised decision support and near patient international normalised ratio (INR) testing: routine data from a practice nurse-led clinic. Family Practice 1998;15:144-6.

\section{STAMPS IN CARDIOLOGY}

\section{Phonocardiography}

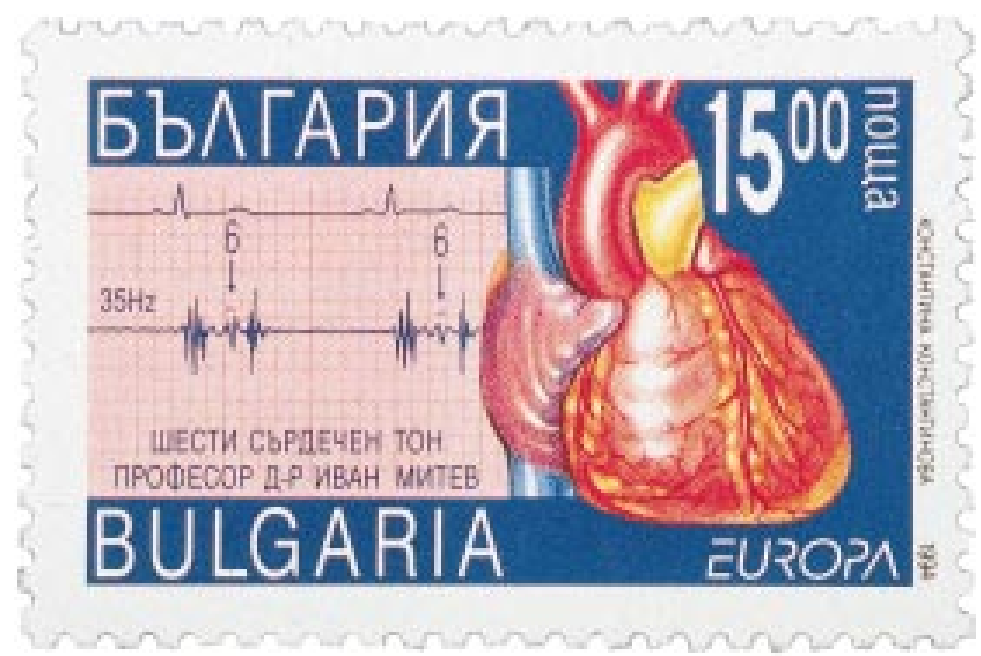

This is the only stamp we have found with a phonocardiogram. The recording shows a late systolic click. It was issued by Bulgaria in 1994 to commemorate the work of Dr Ivan Mitev who described the abnormal sound as the " 6 th tone".

Systolic clicks have been recognised since 1887 when Cuffer and Barbillon reported a "bruit de galop mesosytolique". J N Hall in 1903 and Paul D White in 1931 ascribed late systolic murmurs or clicks as caused by mitral valve dysfunction in opposition to the view of Louis Gallavardin in 1913 that clicks were caused by pleuropericardial adhesions. John Reid in 1961 was the first to state that clicks arose from the mitral chordae-chordal snap. The extensive work by John Barlow in Johannesburg identified many features of nonejection systolic clicks and late mitral systolic murmurs and his contributions are recognised in the term "Barlow's syndrome". 